\title{
Protective effects of red ginseng extract against vaginal herpes simplex virus infection
}

\author{
Ara Cho ${ }^{\#}$, Yoon Seok Roh", Erdenebileg Uyangaa, Surim Park, Jong Won Kim, Kyu Hee Lim, \\ Jungkee Kwon, Seong Kug Eo, Chae Woong Lim, and Bumseok Kim* \\ Biosafety Research Institute and College of Veterinary Medicine, Chonbuk National University, Jeonju 561-756, Korea \\ Edited by Jong-Hoon Kim, Chonbuk National University, Korea
}

\begin{abstract}
Numerous studies have suggested that Korean red ginseng (KRG) extract has various immune modulatory activities both in vivo and in vitro. In this study, we used a mouse model to examine the effects of orally administered KRG extract on immunity against herpes simplex virus (HSV). Balb/c mice were administered with 100, 200, and $400 \mathrm{mg} / \mathrm{kg}$ oral doses of KRG extract for $10 \mathrm{~d}$ and then vaginally infected with HSV. We found that KRG extract rendered recipients more resistant against HSV vaginal infection and further systemic infection, including decreased clinical severity, increased survival rate, and accelerated viral clearance. Such results appeared to be mediated by increased vaginal IFN- $\gamma$ secretion. Moreover, increased mRNA expression of IFN- $\gamma$, granzyme B, and Fas-ligand was identified in the iliac lymph node and vaginal tracts of KRG extract treated groups (200 and $400 \mathrm{mg} / \mathrm{kg}$ ). These results suggest that the activities of local natural killer cells were promoted by KRG extract consumption and that KRG may be an attractive immune stimulator for helping hosts overcome HSV infection.
\end{abstract}

Keywords: Panax ginseng, Korean red ginseng, Herpes simplex virus, Mice, Natural killer cells

\section{INTRODUCTION}

Most infectious agents, including herpes simplex virus (HSV) and human immunodeficiency virus, are mainly transmitted to hosts through mucosal surfaces [1]. Hence, protective innate immunity at mucosal sites is an important issue influencing whether hosts can successfully protect themselves against infection by microorganisms. Mucosal surfaces are one candidate site for vaccine delivery because they combat a wide variety of infectious agents by adaptive immunity. Over the last decade, many studies have investigated the immune systems of the digestive and respiratory tracts. For example, an intranasal vaccination targeting multiple strains of influenza virus has been demonstrated to induce optimal mucosal im-

(c) This is an Open Access article distributed under the terms of the Creative Commons Attribution Non-Commercial License (http://creativecommons.org/licenses/by-nc/3.0/) which permits unrestricted non-commercial use, distribution, and reproduction in any medium, provided the original work is properly cited. mune responses, especially those aided by natural killer (NK) T cells [2]. Currently little is known about the genital mucosal immune system, although many viruses are sexually transmitted through the genital tract. An understanding of both systemic and local mucosal immunity during exposure to infectious agents will provide valuable insight for developing antigen nonspecific immune boosters or vaccines targeting specific antigens.

HSV is among the most successful of infectious agents since it latently infects many immunocompetent human hosts [3]. Clinical symptoms usually occur suddenly in immunocompromised individuals [4]. Mucosal surfaces and injured skin are the major infectious routes of HSV.

Received 17 Oct. 2012, Revised 07 Nov. 2012, Accepted 07 Nov. 2012

${ }^{\#}$ These two authors contributed equally to this work.

*Corresponding author

E-mail: bskims@jbnu.ac.kr

Tel: +82-63-270-4638, Fax: +82-2-63-270-3780 
Mucosal immunity against HSV infection has been observed [5], but there have been limited studies of how to induce such immunity. During the past several decades, traditional or DNA based vaccines have been suggested for protection against HSV infection [4,6]. However, it is unclear whether such an approach will be practically acceptable for the general public because HSV pandemics do not occur. Recently, natural health products have been introduced for immune stimulation $[7,8]$. The prophylactic administration of such immune stimulators might effectively regulate HSV infection.

Panax ginseng is a plant that has been taken orally for various health benefits, including immune stimulation and preventing geriatric diseases. Recently, in vitro and in vivo experiments have revealed the beneficial effects of $P$. ginseng [9-13]. Since the prophylactic administration of ginseng products is more acceptable than therapeutic treatment, its immune modulatory effects (stimulation or regulation) have been studied extensively. Such effects include inducing regulatory $T$ cells in an experimental autoimmune encephalitis model [9], increasing NK cell population in mice [8] and activity in vitro [10], stimulating nitric oxide synthesis in a macrophage cell line [11], and attenuating the toll-like receptor (TLR) ligand-induced activation of dendritic cells [14]. It is still unclear whether the immune stimulatory action of prophylactic ginseng administration attenuates disease progress caused by specific pathogens. Here, we assessed the protective effects of Korean red ginseng (KRG) extract against HSV infection. In present study, the administration of KRG extract rendered mice more resistant to HSV vaginal and systemic infection. Such results might be caused by increased NK cell activity.

\section{MATERIALS AND METHODS}

\section{Reagents}

KRG extract was kindly provided by the Korea Ginseng Corporation (Daejeon, Korea). It was dissolved in distilled water at final concentrations of 20,40 , or $80 \mathrm{mg}$ / $\mathrm{mL}$ and kept frozen until use $\left(-80^{\circ} \mathrm{C}\right)$.

\section{Animal}

Seven-week-old female Balb/c mice were purchased from Samtako Bio Korea (Osan, Korea). Mice were housed in polycarbonate cages in an animal facility under standard conditions $\left(24 \pm 2^{\circ} \mathrm{C}, 50 \pm 5 \%\right.$ humidity) with a $12 \mathrm{~h}$ light/dark cycle. The Institutional Animal Care and Use Committee of Chonbuk National University approved the care and use of animals reported in this study.

\section{Experimental protocol}

Mice were randomly divided into four groups of control (distilled water) and KRG (100, 200, and $400 \mathrm{mg} / \mathrm{kg}$ ) treatment. KRG extract was orally administered every day for $10 \mathrm{~d}$. HSV-1 McKrae strain was propagated in Vero cells (CCL81; ATCC, Manassas, VA, USA) using Dulbecco's-modified Eagle's medium (DMEM) containing $2.5 \%$ fetal bovine serum (FBS), penicillin (100 U/ $\mathrm{mL})$, and streptomycin $(100 \mathrm{U} / \mathrm{mL})$. The virus stocks were titrated using a plaque assay and were stored in aliquots at $-80^{\circ} \mathrm{C}$ until use.

\section{Vaginal challenge}

The mice were treated with progesterone to synchronize their estrus cycles. Briefly, mice were subcutaneously injected with $10 \mathrm{mg}$ medroxyprogesterone 17-acetate (Sigma-Aldrich, St. Louis, MO, USA). Five days following the injection and one day after the last administration of KRG extract, mice were intravaginally challenged with $10^{6}$ PFU of HSV-1 McKrae. Mice were examined daily and scored from 0 to 5 depending on the clinical severity of disease $(0$, no change; 1 , mild inflammation of vagina; 2 , moderate inflammation and swelling of vagina; 3, severe inflammation and swelling of vagina; 4 , paralysis; 5, death).

\section{Viral titration}

Vaginal washings were collected by pipetting and recovering $100 \mu \mathrm{L}$ of phosphate-buffered saline (PBS) in the vaginal cavity on different days ( 2 to 5 days post infection, dpi) after the vaginal challenge. Samples were stored at $-80^{\circ} \mathrm{C}$ until use. Individual samples were thawed in ice and further diluted, and viral titration was performed by a plaque assay on Vero cells as described elsewhere [15]. To determine the effects of KRG extract on viral infectivity, $10^{2}$ PFU HSV-1 McKrae were applied to Vero cells with DMEM media containing final concentrations of 100,200 , or $400 \mu \mathrm{g} / \mathrm{mL} \mathrm{KRG}$ extract. After $3 \mathrm{~d}$ of incubation in a $\mathrm{CO}_{2}$ incubator, a plaque assay was performed as described earlier.

\section{Measurement of vaginal IFN- $\gamma$ secretion}

To measure IFN- $\gamma$ secretion, vaginal lavage fluid was collected from the vaginal cavity using the same method as the vaginal washings with viral titration (0 to $6 \mathrm{dpi}$ ). Samples were stored at $-80^{\circ} \mathrm{C}$ until use. Individual samples were thawed in ice, and vaginal mucus was removed from the fluid by centrifugation at 12,000 rpm for $1 \mathrm{~min}$. IFN- $\gamma$ concentration in vaginal fluid was measured by sandwich enzyme-linked immunosorbent assay (ELISA). 
Table 1. Primer sequences used for real time polymerase chain reaction

\begin{tabular}{ll}
\hline RNA target & \multicolumn{1}{c}{ Primer sequences } \\
\hline IFN- $\gamma$ & F: 5'- TTAACTCAAGTGGCATAGATGTGGAAG -3' \\
& R: 5'- TGACGCTTATGTTGTTGCTGATGG -3' \\
Granzyme B & F: 5'-GGCCTGCACAGCCTTCAT-3' \\
& R: 5'-CAGGGTGTTTAATGGCTTGCTT-3' \\
Perforin & F: 5'-GGAAGCAAACGTGCATGTGT-3' \\
& R: 5'-TCGGCTGCAAAATTGGCTAT-3' \\
Fas ligand & F: 5'-GGCTGGGTGCCATGCA-3' \\
& R: 5'-GGAGAAGTGGCACTGCTGTCT-3' \\
GAPDH & F: 5'-ACGGCAAATTCAACGGCACAG-3' \\
& R: 5'-AGACTCCACGACATACTCAGCAC-3'
\end{tabular}

$F$, forward; $R$, reverse.

Briefly, ELISA plates (Greiner Bio-One, Frickenhausen, Germany) were coated with purified anti-mouse IFN- $\gamma$ antibody $(1: 1,000)$ (eBiosciences, San Diego, CA, USA) and incubated at $4{ }^{\circ} \mathrm{C}$ overnight. The plates were washed with $0.05 \%$ Tween $20 / \mathrm{PBS}$ and blocked with $10 \%$ FBS/ PBS for $1 \mathrm{~h}$ at room temperature. After washing, serial two-fold diluted vaginal lavage fluid and standard IFN- $\gamma$ protein were added to wells and incubated overnight at $4{ }^{\circ} \mathrm{C}$. Biotin-conjugated anti-mouse IFN- $\gamma$ antibodies (1:500) (eBiosciences) were added to the wells after washing, and wells were incubated at room temperature for $1 \mathrm{~h}$. Avidin horseradish peroxidase (eBiosciences) was added to the plates for cytokine detection. A 3,3',5,5'-tetramethylbenzidine (TMB) substrate reagent set (BD Biosciences, San Jose, CA, USA) was used for color development, and the reaction was stopped with $2 \mathrm{M} \mathrm{H}_{2} \mathrm{SO}_{4}$. Plate reading was conducted at $450 \mathrm{~nm}$ using an ELISA reader.

\section{Quantitative real-time polymerase chain reaction}

Total RNA was extracted from different mouse tissues, including the spleen, iliac lymph nodes, and vagina, using an Easy-Spin Total RNA extraction kit (iNtRon Biotech, Seoul, Korea). Both nucleic acid concentration and purity (A260/A280) were measured with a NanoDrop ND-1000 (NanoDrop Technologies, Wilmington, DE, USA). Following incubation with RNase-free DNase I (Promega, Madison, WI, USA), reverse transcription was performed using a PrimeScript RT reagent kit (Takara Bio Inc., Shiga, Japan) according to the manufacturer's instructions. The resulting cDNA was subjected to realtime polymerase chain reaction (PCR) on a CFX96 RealTime PCR Detection System (Bio-Rad Laboratories, Hercules, CA, USA) using SYBR Green I as a doublestrand DNA-specific binding dye to quantify expression for IFN- $\gamma$, granzyme B, perforin, Fas ligand (FasL),
mRNA. PCR amplifications were performed with individual primers in a total volume of $20 \mu \mathrm{L}$ containing 5 pmol of each primer (Table 1), $10 \mu \mathrm{L}$ of $2 \times$ SYBR Premix Ex Taq II (Takara Bio Inc.), and nuclease-free PCR-grade water after initial denaturation at $95^{\circ} \mathrm{C}$ for $10 \mathrm{~s}$ and 45 cycles $\left(95^{\circ} \mathrm{C}\right.$ for $5 \mathrm{~s}$ and $61^{\circ} \mathrm{C}$ for $\left.30 \mathrm{~s}\right)$. The forward and reverse primers are shown in Table 1. After the reaction was completed, specificity was verified by melting curve analysis. Quantification was performed by comparing $\mathrm{Ct}$ values of each sample with normalization to GAPDH.

\section{Statistical analysis}

All data were expressed as mean \pm standard error. Differences between multiple groups were compared with one-way analysis of variance (ANOVA) using SAS ver. 9.1 (SAS Institute Inc., Cary, NC, USA). Individual comparisons were obtained by Duncan's multiple range test.

\section{RESULTS}

\section{Korean red ginseng administered mice are resis- tant to mucosal herpes simplex virus infection}

To assess the effects of KRG extract on mucosal HSV infection, Balb/c female mice were orally administered KRG extracts $(0,100,200,400 \mathrm{mg} / \mathrm{kg}$ body weight) by oral gavage for $10 \mathrm{~d}$. At one day post final administration, mice were intravaginally challenged with $10^{6} \mathrm{PFU}$ of HSV-1 McKrae. Clinical severity (vaginal inflammation, neurological illness, and death) was scored daily. As shown in Fig. 1, mice that received KRG extract solution (200 and $400 \mathrm{mg} / \mathrm{kg}$ ) showed less clinical severity and higher survival rates against HSV infection. However, the $100 \mathrm{mg} / \mathrm{kg} \mathrm{KRG}$ extract treatment group did not show this clinical pattern. These results suggest that the administration of KRG extracts could provide protective effects against mucosal HSV infection.

\section{Treatment with KRG accelerated viral clearance and increased IFN- $\gamma$ levels in the vaginal tracts of herpes simplex virus infected mice}

To investigate how KRG extract treated groups were resistant to HSV infection, the effects of viral clearance were measured in the vaginal tracts of mice at various times after infection. As indicated in Fig. 2A, the average virus titer in vaginal tracts of mice that received $\mathrm{KRG}$ extract was lower than that of the control group at 2, 3, and 4 dpi. Moreover, viral clearance was accelerated in the KRG extract treated mice (200 and $400 \mathrm{mg} / \mathrm{kg}$ ) at day 5 
A

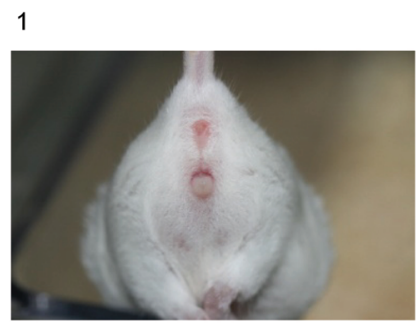

4

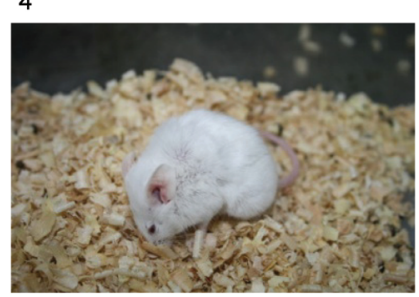

2

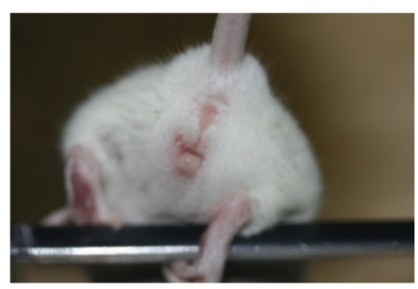

5

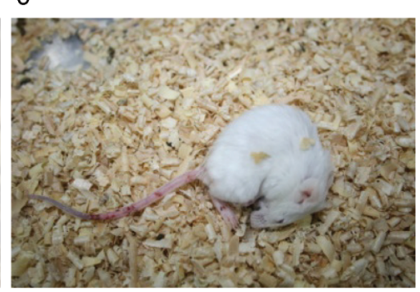

3
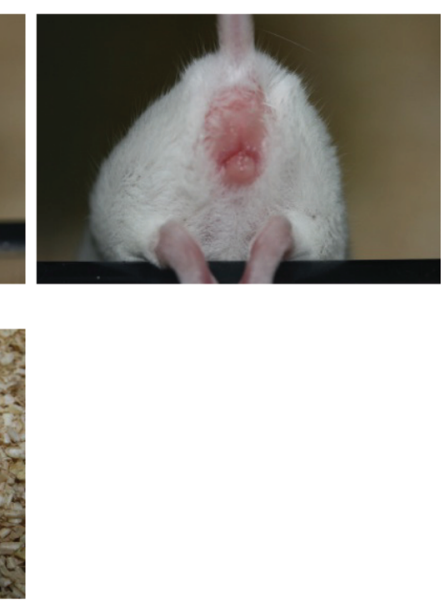

B
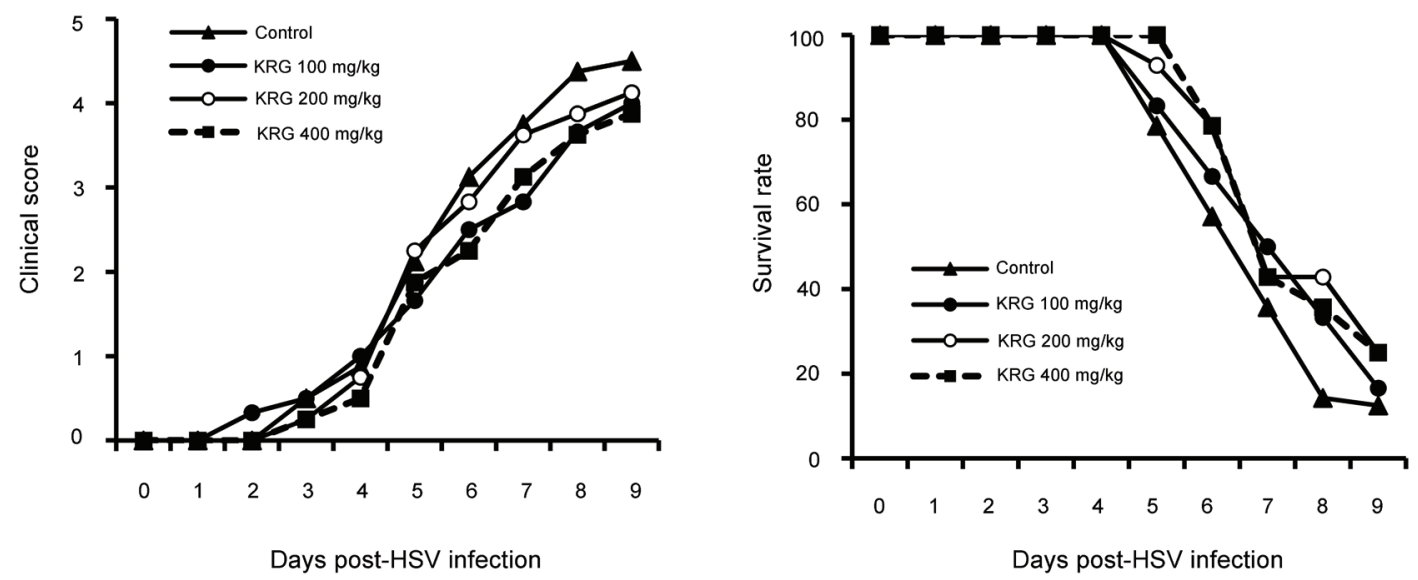

Fig. 1. Clinical severity of Korean red ginseng (KRG) administered mice undergoing vaginal herpes simplex virus (HSV) challenge. One day after final KRG extract $\left(0,100,200,400 \mathrm{mg} / \mathrm{kg}\right.$ ) administration, mice were intravaginally infected with HSV McKrae strain (10 ${ }^{6}$ PFU). Mice were examined daily for vaginal inflammation, neurological illness, and death. Vaginal clinical severity scores were judged as follows: 0 , no inflammation; 1 , mild inflammation; 2, moderate inflammation and swelling; 3, severe inflammation and swelling; 4, neurologic manifestations such as paralysis; 5 , death (A). Average clinical scores and survival rates were obtained using seven mice per group (B).

post infection, indicating that antiviral events occurred in the KRG extract treated group.

Since the increase in IFN- $\gamma$ secretion with two peaks (days 2 and 5 post HSV infection) is the most pronounced in the HSV infected vaginal tract and IFN- $\gamma$ is the primary cytokine that defines protective Th1 or NK cells against mucosal HSV infection [16,17], IFN- $\gamma$ protein levels were measured with vaginal washes. The results are shown in Fig. 2B. The recipients of KRG extract (200 and $400 \mathrm{mg} / \mathrm{kg}$ ) had higher levels of IFN- $\gamma$ in vaginal washes than control mice, with two secretion peaks observed (first and second peaks on days 2 and 5 post challenge). In addition, the start of IFN- $\gamma$ secretion was accelerated in the vaginal washes of mice treated with $400 \mathrm{mg} / \mathrm{kg} \mathrm{KRG}$ compared to other groups. This suggests that local immune activities start early in the KRG extract group and that increased IFN- $\gamma$ production in the vaginal tract of KRG extract administered mice enhanced virus clearance. Such conditions may potentially affect clinical severity and survival rates related to HSV vaginal infection.

Treatment with KRG extract increased the IFN- $\gamma$ levels in the iliac lymph node and vaginal tissue of herpes simplex virus infected mice

Since dramatically increased IFN- $\gamma$ secretion was 
A
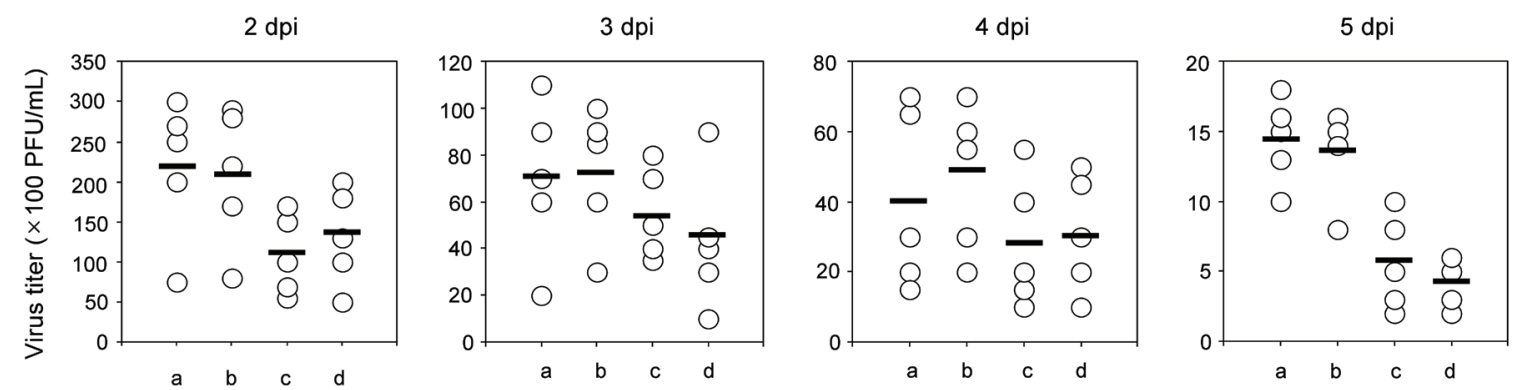

B

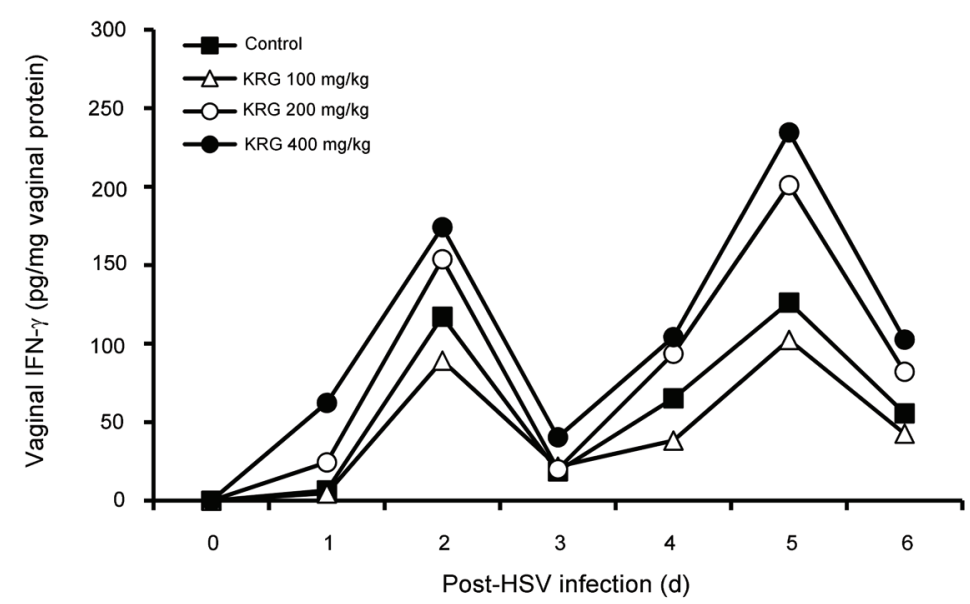

Fig. 2. Viral clearance and vaginal IFN-y secretion following vaginal infection with herpes simplex virus (HSV) in mice administered with Korean red ginseng (KRG) extract. Influence of KRG administration on HSV clearance (A). KRG administered mice $(n=5)$ were intravaginally challenged with HSV, and vaginal lavage fluid was collected on days 2, 3, 4, and 5 after virus infection. Virus titers were determined by plaque assay. Open circles represent individual virus titers and black lines represent average virus titers. (a) Control, (b) KRG 100 mg/kg, (c) KRG 200 mg/kg, and (d) KRG $400 \mathrm{mg} / \mathrm{kg}$. (B) Vaginal IFN-y concentrations were determined by sandwich enzyme-linked immunosorbent assay, and each concentration was adjusted for vaginal protein content. Results are expressed as a mean for four mice. dpi, day post infection.

evident in the vaginal washes of KRG treated groups after HSV infection, IFN- $\gamma$ mRNA expression was measured in the spleen, iliac lymph node, and vaginal tissue of animals on day 2 post challenge. As indicated in Fig. 3, IFN- $\gamma$ mRNA expression was slightly higher in the iliac lymph node and vagina of the HSV infected control group than in the non-infected group, but there was no significant difference. Markedly increased IFN- $\gamma$ mRNA expression was detected in the iliac lymph node and vaginal tissue of mice treated with KRG extract (200 and $400 \mathrm{mg} / \mathrm{kg}$ ) compared to mock or HSV infected control mice. However, there was no significant difference between groups regarding IFN- $\gamma$ mRNA expression in the spleen. These findings indicate that local protective immune responses were increased in mice treated with KRG extract (200 and $400 \mathrm{mg} / \mathrm{kg}$ ).

\section{Expression of molecules related to natural killer cell activities was increased in Korean red ginseng extract administered mice}

Since IFN- $\gamma$ secretion was evident on day 1 post infection and IFN- $\gamma$ levels remained high in the vaginal tract of KRG extract treated animals until day 6 post infection, NK cells might be a major source of IFN- $\gamma$ secretion in the vaginal tract. To investigate this hypothesis, the mRNA expression of molecules related to NK cell activities was measured in the spleen, iliac lymph node, and vaginal tract on day 2 post infection. Measured molecules included granzyme B, perforin, and FasL. The expression pattern of granzyme B, perforin, and FasL mRNA in the spleen was not different for control and KRG extract consumed groups (Fig. 4). In the iliac lymph nodes, expression of granzyme B $(400 \mathrm{mg} / \mathrm{kg})$ and FasL (200 and $400 \mathrm{mg} / \mathrm{kg}$ ) mRNA was higher in KRG treated mice 


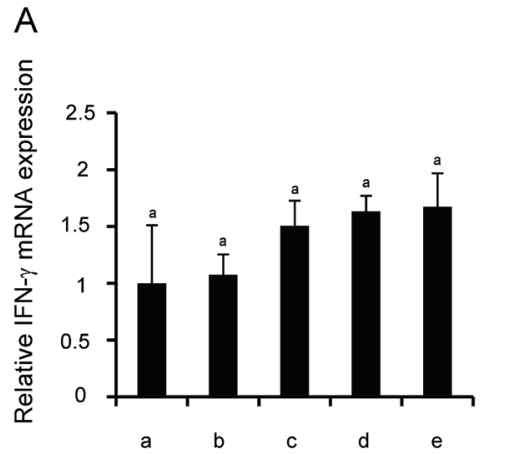

B

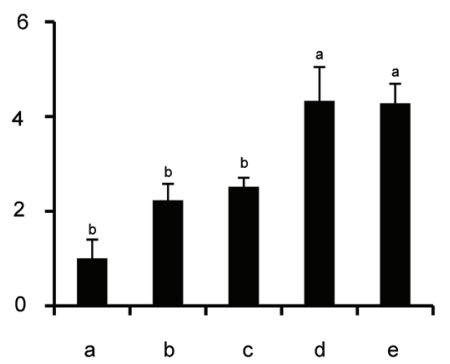

C

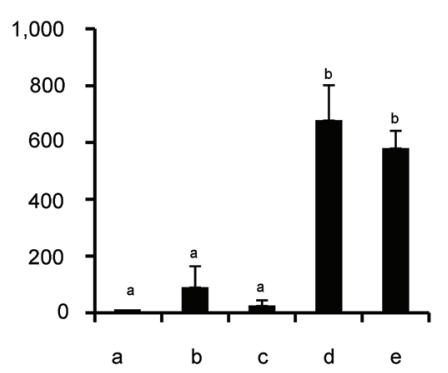

Fig. 3. IFN-y mRNA expression in (A) spleen, (B) iliac lymph node, and (C) vaginal tissue after vaginal herpes simplex virus (HSV) infection in mice administered with Korean red ginseng (KRG) extract. KRG administered mice $(n=7)$ were intravaginally challenged, and each organ was collected on day 2 after virus infection. IFN-y mRNA was measured by real time polymerase chain reaction and relative expression levels were normalized. (a) Mock control, (b) HSV infected control, (c) KRG $100 \mathrm{mg} / \mathrm{kg}$, (d) KRG $200 \mathrm{mg} / \mathrm{kg}$, and (e) KRG $400 \mathrm{mg} / \mathrm{kg}$. Data are presented as means \pm SEM for each group. Different letters indicate significant differences $(p<0.05)$ according to Duncan's multiple range test.
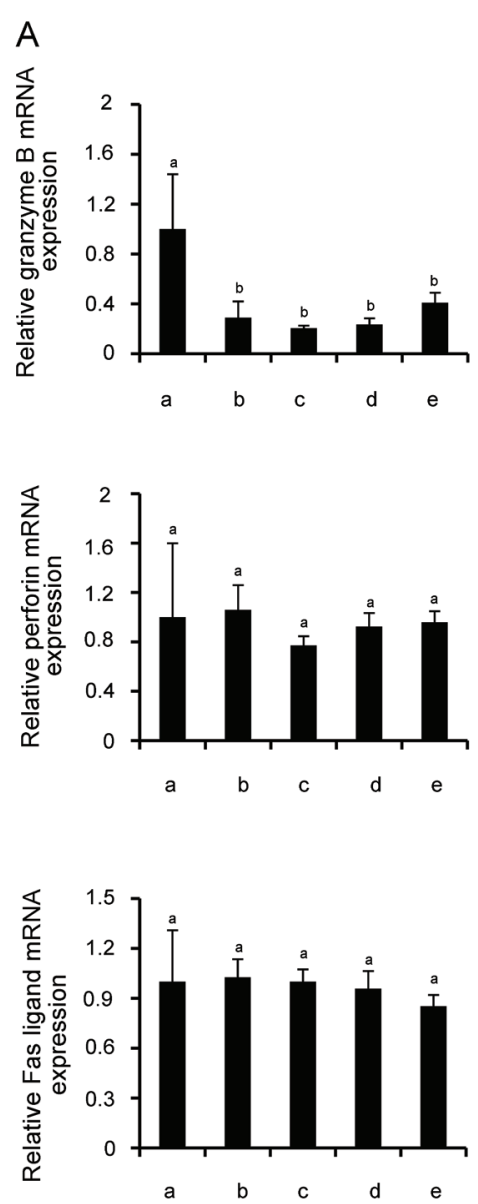

B
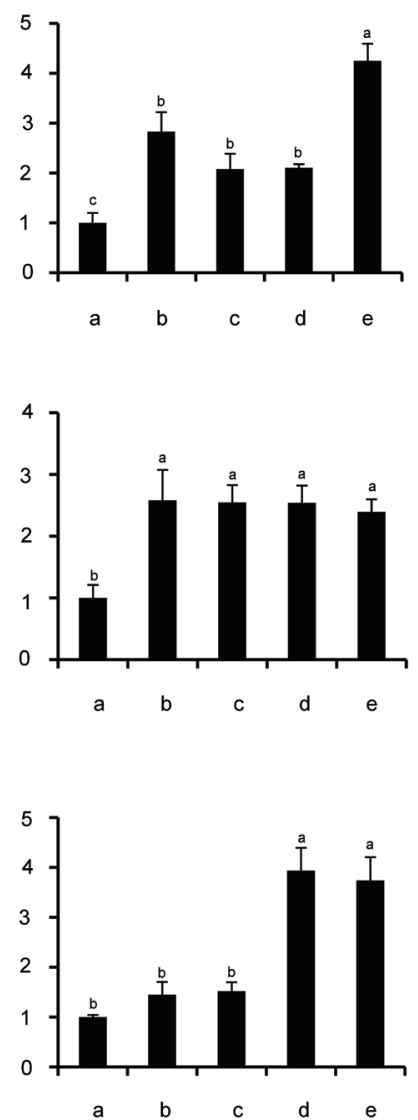

C
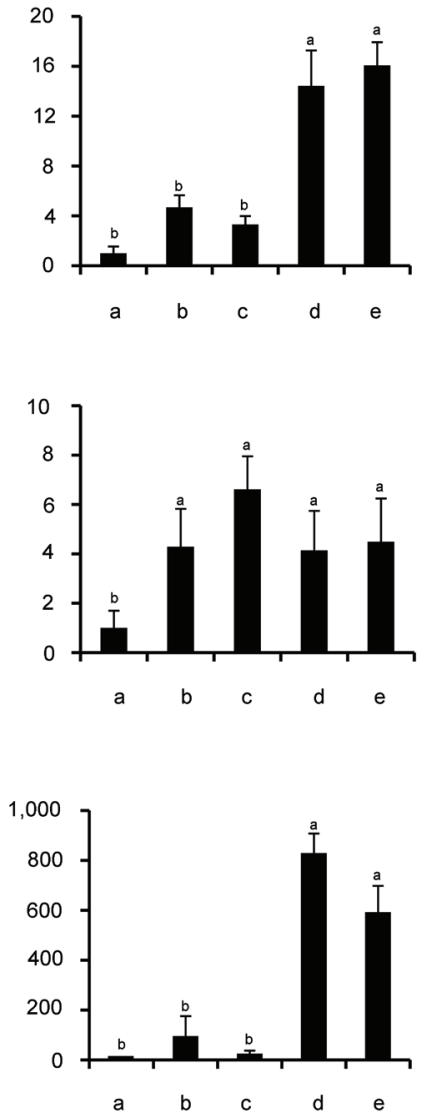

Fig. 4. mRNA expression of granzyme B, perforin, and Fas ligand, cytolytic related molecules in (A) spleen, (B) iliac lymph node, (C) vaginal tissue. Korean red ginseng (KRG) administered mice $(n=7)$ were intravaginally challenged, and each organ was collected on day 2 after virus infection. The mRNA of each molecule was measured by real time polymerase chain reaction and relative expression levels were normalized. (a) Mock control, (b) herpes simplex virus infected control, (c) KRG $100 \mathrm{mg} / \mathrm{kg}$, (d) KRG $200 \mathrm{mg} / \mathrm{kg}$, and (e) KRG $400 \mathrm{mg} / \mathrm{kg}$. Data are presented as means \pm SEM for each group. Different letters indicate significant differences $(p<0.05)$ according to Duncan's multiple range test.

than those seen in the HSV infected control group. However, HSV infected groups had no difference in perforin
mRNA expression. In vaginal tract tissue samples, the mRNA expression of granzyme B and FasL was marked- 

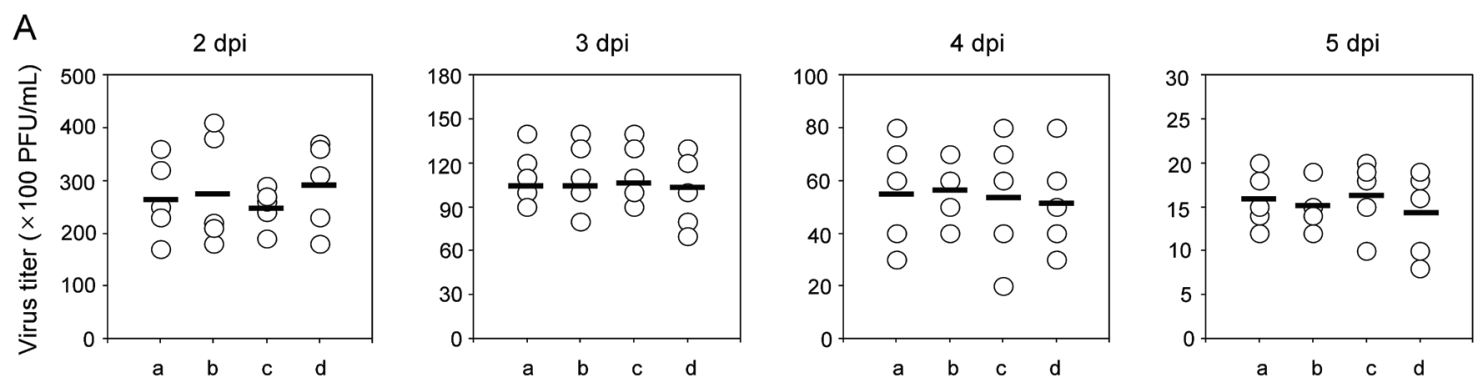

B

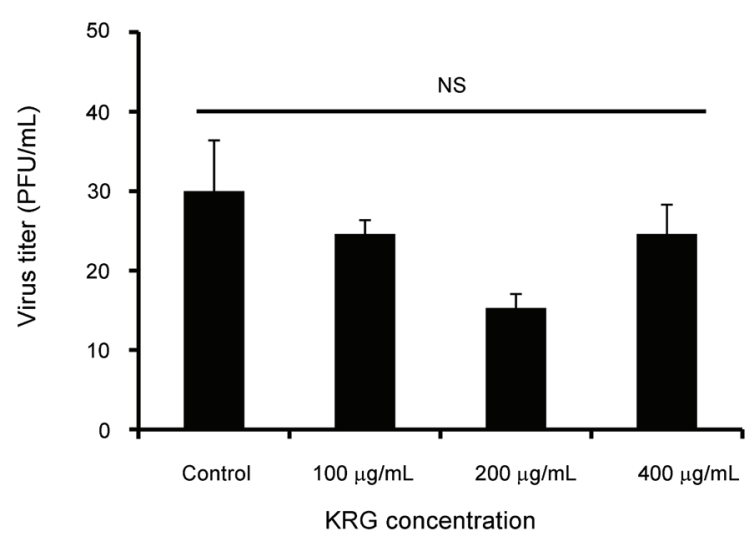

Fig. 5. Effects of Korean red ginseng (KRG) treatment on herpes simplex virus (HSV) infectivity in vivo and in vitro. Influence of KRG vaginal treatment on HSV clearance (A). HSV infected mice $(n=5)$ were intravaginally treated with KRG extract solution at $2 \mathrm{~h}$ post challenge, and vaginal lavage fluid was collected on days 2, 3, 4, and 5 after virus infection. Virus titers were determined by plaque assay. Open circles represent individual virus titers and black lines represent average virus titers. (a) Control, (b) KRG $100 \mu \mathrm{g} / \mathrm{mL}$, (c) KRG $200 \mu \mathrm{g} / \mathrm{mL}$, and (d) KRG $400 \mu \mathrm{g} / \mathrm{mL}$. HSV treated Vero cells were incubated with no serum Dulbecco's-modified Eagle's medium media containing different concentrations of KRG extract for $3 \mathrm{~d}$, and plaque assay was performed (B). Data are presented as means $\pm S E M$ for each group. NS indicates non-significant difference between groups. dpi, day post infection.

ly higher than those seen in KRG extract treated groups (200 and $400 \mathrm{mg} / \mathrm{kg}$ ) than in HSV infected control mice. These results suggest that KRG extract administration enhances NK cell activities via the up-regulation of granzyme B and FasL pathways in local lymph nodes and the infected organ. These results suggested that granzyme B and FasL might regulate HSV vaginal infection.

\section{Treatment with Korean red ginseng extract did not affect herpes simplex virus infectivity in vivo or in vitro}

The present study was designed to explore alternative mechanisms by which KRG directly influences HSV infectivity. To determine such effects, HSV infected mice were vaginally treated with $\mathrm{KRG}$ extract solution (0, 100,200 , and $400 \mu \mathrm{g} / \mathrm{mL}$ ) at $2 \mathrm{~h}$ post infection. The virus titer in the vaginal tract was measured at different dpi. As indicated in Fig. 5A, average virus titers were similar for all groups, suggesting that KRG extract itself does not affect HSV infectivity. HSV was used to infect Vero cells with media containing various concentrations of KRG extract, and a plaque assay was performed at 3 dpi (Fig. 5B). As expected, HSV infectivity was not affected by the presence of KRG extract. Therefore, the direct effects of KRG on HSV infectivity were not discovered.

\section{DISCUSSION}

In this study, we demonstrate that administration of $\mathrm{KRG}$ extracts on a prophylactic basis regulates vaginal and systemic HSV infectivity. These beneficial effects have been suggested to involve increased expression of IFN- $\gamma$, granzyme B, and FasL in the iliac lymph nodes and vaginal tissue, presumably by enhanced NK cell activities.

Large numbers of immune stimulators have recently been discovered, and many studies have scientifically demonstrated their effects on various immune systems. However, excessive immune stimulation results in several side effects, such as the development of immunotoxicity and hypersensitivity. Experimental models are needed to verify immune stimulatory activities that increase host 
resistance to microbial infection. Here, we investigated whether KRG extract administration efficiently boosts the immune system and protects KRG administered mice against HSV mucosal infection. Since different parts of immune cells regulate HSV, KRG related immune modulation can be either beneficial or detrimental to the host. For example, increased activation of certain TLRs, including TLR2, 3, and 6, induces the innate antiviral pathway $[18,19]$ and acquired HSV specific $\mathrm{CD}^{+}[5,20]$ and $\mathrm{CD} 8^{+} \mathrm{T}$ cells [21]. Furthermore, regulatory $\mathrm{T}$ cells coordinate early protective immunity to HSV infection, although their exact function is not yet understood. We hypothesized that KRG extract administration would modulate the immune environment and affect genital HSV infectivity.

Many controversial studies have shown that ginseng inhibits TLR-mediated inflammatory signals [14] or induces the production of proinflammatory cytokines via TLR signaling [22]. These studies suggest that ginseng differentially modulates TLR signaling depending on different TLR classes and disease models. In our previous preliminary study, KRG treatment (20 and $100 \mu \mathrm{g} / \mathrm{mL}$ ) induced the production of IL-1 $\beta$ (under TLR3 ligand stimulation) and TNF- $\alpha$ (under TLR2 or TLR9 ligand stimulation) from a macrophage cell line stimulated with different TLR ligands (data not shown). Furthermore, the expression of TLR2 and 3 was significantly reduced in the mesenteric lymph node and spleen of mice treated with KRG extract (200 and $400 \mathrm{mg} / \mathrm{kg}$ ) for $10 \mathrm{~d}$ (data not shown). These results indicate that KRG has diverse effects on TLR-related signaling and that such effects might affect genital HSV infectivity. Although the present study does not provide detailed information regarding the relationship between KRG and TLR signaling and HSV infection, future studies will attempt more detailed analyses of their activities.

Increased expression of IFN- $\gamma$, granzyme B, and FasL in the iliac lymph node and vaginal tissue indicates robust local antiviral immunity in mice treated with KRG. Although the source of IFN- $\gamma$ varies, granzyme B and FasL related killing of virus infected cells mainly occurs by NK cells. Our findings are in general agreement with the previous finding that treatment with ginseng induces NK cell activity $[8,10]$. In another study, we found that the population of NK, CD4, CD8, and Foxp3 positive cells did not change in the iliac lymph nodes of KRG extract administered mice (data not shown). Such results indicate that KRG administration does not affect the quantity of NK cells, but does increase the quality of NK cells. This study did not mechanistically demonstrate how KRG administration increases NK cell activity by up-regulating IFN- $\gamma$, granzyme B, and FasL expression. Therefore, a further detailed study is under investigation.

In summary, we demonstrated the protective effects of $\mathrm{KRG}$ in HSV infected mice. Increases in antiviral IFN- $\gamma$, granzyme B, and FasL regulate HSV infectivity, which reduces HSV-related clinical severity. The present study demonstrates additional prophylactic effects of KRG that will pave the way for developing and evaluating dietary immunestimulators.

\section{ACKNOWLEDGEMENTS}

This study was supported by a grant from Korean Society of Ginseng (2010).

\section{REFERENCES}

1. Eo SK, Lee S, Chun S, Rouse BT. Modulation of immunity against herpes simplex virus infection via mucosal genetic transfer of plasmid DNA encoding chemokines. J Virol 2001;75:569-578.

2. Bird L. Mucosal vaccines: NKT cells help fight flu. Nat Rev Immunol 2008;8:402-403.

3. Johnson AJ, Chu CF, Milligan GN. Effector CD4+ T-cell involvement in clearance of infectious herpes simplex virus type 1 from sensory ganglia and spinal cords. J Virol 2008;82:9678-9688.

4. Kuklin N, Daheshia M, Karem K, Manickan E, Rouse BT. Induction of mucosal immunity against herpes simplex virus by plasmid DNA immunization. J Virol 1997;71:3138-3145.

5. Kwant-Mitchell A, Ashkar AA, Rosenthal KL. Mucosal innate and adaptive immune responses against herpes simplex virus type 2 in a humanized mouse model. J Virol 2009;83:10664-10676.

6. Kim SB, Han YW, Rahman MM, Kim SJ, Yoo DJ, Kang SH, Kim K, Eo SK. Modulation of protective immunity against herpes simplex virus via mucosal genetic cotransfer of DNA vaccine with beta2-adrenergic agonist. Exp Mol Med 2009;41:812-823.

7. Hu S, Concha C, Lin F, Persson Waller K. Adjuvant effect of ginseng extracts on the immune responses to immunisation against Staphylococcus aureus in dairy cattle. Vet Immunol Immunopathol 2003;91:29-37.

8. Miller SC, Ti L, Shan J. Dietary supplementation with an extract of North American ginseng in adult and juvenile mice increases natural killer cells. Immunol Invest 2012;41:157-170.

9. Hwang I, Ahn G, Park E, Ha D, Song JY, Jee Y. An acidic 
polysaccharide of Panax ginseng ameliorates experimental autoimmune encephalomyelitis and induces regulatory T cells. Immunol Lett 2011;138:169-178.

10. See DM, Broumand N, Sahl L, Tilles JG. In vitro effects of echinacea and ginseng on natural killer and antibodydependent cell cytotoxicity in healthy subjects and chronic fatigue syndrome or acquired immunodeficiency syndrome patients. Immunopharmacology 1997;35:229235.

11. Friedl R, Moeslinger T, Kopp B, Spieckermann PG. Stimulation of nitric oxide synthesis by the aqueous extract of Panax ginseng root in RAW 264.7 cells. Br J Pharmacol 2001;134:1663-1670.

12. Yang H, Lee SE, Jeong SI, Park CS, Jin YH, Park YS. Up-regulation of heme oxygenase-1 by Korean red ginseng water extract as a cytoprotective effect in human endothelial cells. J Ginseng Res 2011;35:352-359

13. Bae J, Koo J, Kim S, Park TY, Kim MY. Ginsenoside Rp1 exerts anti-inflammatory effects via activation of dendritic cells and regulatory T cells. J Ginseng Res 2012;36:375382 .

14. Rhule A, Rase B, Smith JR, Shepherd DM. Toll-like receptor ligand-induced activation of murine DC2.4 cells is attenuated by Panax notoginseng. J Ethnopharmacol 2008;116:179-186.

15. Spear PG, Roizman B. Proteins specified by herpes simplex virus. V. Purification and structural proteins of the herpesvirion. J Virol 1972;9:143-159.

16. Gill N, Chenoweth MJ, Verdu EF, Ashkar AA. NK cells require type I IFN receptor for antiviral responses during genital HSV-2 infection. Cell Immunol 2011;269:29-37.
17. Bettahi I, Zhang X, Afifi RE, BenMohamed L. Protective immunity to genital herpes simplex virus type 1 and type 2 provided by self-adjuvanting lipopeptides that drive dendritic cell maturation and elicit a polarized Th1 immune response. Viral Immunol 2006;19:220-236.

18. Rose WA 2nd, McGowin CL, Pyles RB. FSL-1, a bacterial-derived toll-like receptor $2 / 6$ agonist, enhances resistance to experimental HSV-2 infection. Virol J 2009; 6:195.

19. Reinert LS, Harder L, Holm CK, Iversen MB, Horan KA, Dagnæs-Hansen F, Ulhoi BP, Holm TH, Mogensen TH, Owens $\mathrm{T}$ et al. TLR3 deficiency renders astrocytes permissive to herpes simplex virus infection and facilitates establishment of CNS infection in mice. J Clin Invest 2012;122:1368-1376.

20. Dasgupta G, Chentoufi AA, You S, Falatoonzadeh P, Urbano LA, Akhtarmalik A, Nguyen K, Ablabutyan L, Nesburn AB, BenMohamed L. Engagement of TLR2 reverses the suppressor function of conjunctiva CD4+CD25+ regulatory $\mathrm{T}$ cells and promotes herpes simplex virus epitope-specific CD4+CD25- effector T cell responses. Invest Ophthalmol Vis Sci 2011;52:3321-3333.

21. Zhang X, Chentoufi AA, Dasgupta G, Nesburn AB, Wu M, Zhu X, Carpenter D, Wechsler SL, You S, BenMohamed L. A genital tract peptide epitope vaccine targeting TLR2 efficiently induces local and systemic CD8+ T cells and protects against herpes simplex virus type 2 challenge. Mucosal Immunol 2009;2:129-143.

22. Nakaya TA, Kita M, Kuriyama H, Iwakura Y, Imanishi J. Panax ginseng induces production of proinflammatory cytokines via toll-like receptor. J Interferon Cytokine Res 2004;24:93-100. 